\title{
PIEZOELECTRIC POWER GENERATOR FROM SMART HYBRID LAMINATED POLYMER COMPOSITE TILES
}

\author{
R. VENKATAKRISHNAN ${ }^{1}$, P.THILIPAN ${ }^{2} \&$ K. SRINIVAS ${ }^{3}$ \\ ${ }^{I}$ Assistant Professor, Department of Mechanical Engineering, IFET College of Engineering, Villupuram, Tamil Nadu, India \\ ${ }^{2,3}$ UG Student, Department of Mechanical Engineering, IFET College of Engineering, Villupuram, Tamil Nadu, India
}

\begin{abstract}
The individuals has required and used energy at a increasing rate since a protracted time with the energy consumption because of giant growing sort of electronic devices, the great effort has been taken to hunt out eco-friendly and renewable energy sources, the foremost mode renewable energy sources has high initial investment (such as energy, hydropower, star power). Thought of utilization of foot power is incredibly vital for much inhabited countries like Asian country, China wherever the temples and railway stations square measure overcrowded all around the clock. One in every of the foremost fascinating strategies to getting energy by close a system is to use electricity material. The electricity material has crystalline structure which supply to ability convert mechanical pressure to electricity or the opposite way around. By mistreatment electricity material, to fabricate $E$ fibre bolstered compound composite tiles. It isn't possible to interchange this electricity generation, however a minimum of to require issue and reduce the reliance on the normal electricity generation. Electricity device square measure attached within the composite tiles in series-parallel affiliation. In this methodology is one in every of the compact and good systems for generating electricity which could be simply put in several areas. And this power has several applications as in agriculture, street lighting, and residential applications.

KEYWORDS: Polymer Composite, Green Energy, Piezoelectric Effect, Transducer, Composite Tiles
\end{abstract}

Received: Jun 08, 2020; Accepted: Jun 28, 2020; Published: Sep 09, 2020; Paper Id.: IJMPERDJUN20201125

\section{INTRODUCTION}

In everyday life strength has come to be a lifestyles saver for human populace. Then again, human populace round all over the world makes use of electricity in daily life. As desires be it is vital to produce electric energy with the expanding of human populace. The piezoelectric substances is ability to produce power when a peoples walk. This innovation depends on piezoelectric effect, which has potential to deliver electric strength by giving mechanical strain. This method of electricity harvesting is new and non-conventional technique.

A composite material is organized with the aid of combining two or extra substances often ones that have very distinctive properties. The two substances work collectively to give the composite special properties. The largest gain of current composite substances is that they are mild as well as strong. By deciding on an terrific combination of matrix and reinforcement fabric a new fabric can be made that precisely meets the necessities of a precise application. Composites additionally supply diagram flexibility. Because, many of them can be molded into complicated shapes. Here, Matrix fabric used Epoxy resin and Reinforcement fabric is E-glass in the ratio of 10:1 for Composite tiles.

General chemical configuration of piezoelectric thinks consists of Common piezoelectric man made ceramics consist of lead titanate, barium-titanate and lead zirconatetitanate the most frequent piezoelectric ceramic 
in use. Naturally occurring piezoelectric materials include tendons, silk, bone, some woods, enamel, dentin and collagen.

In day to day life electrical energy has come to be a lifeline for human population. On the other hand, human populace around all over the world makes use of electrical energy in day to day life. Accordingly it is necessary to generate electric electricity with the increasing of human population. This science is based on piezoelectric effect, which has capacity to produce electric electricity by using giving mechanical strain. The piezoelectric harvesting is new and progressive technique of harvesting energy. Harvesting of electricity means strength is already on hand however it is going to waste if it is utilized. In this paper provide an explanation for about the higher piezoelectric cloth to get electric powered power.

\section{MATERIALS AND METHODS}

\section{Piezoelectric Sensor}

Piezoelectric Sensor fabric has a crystalline structure It is potential to convert mechanical strain to electrical energy. Piezoelectric sensor cloth is the important component of the project. It is belongs to the group of ferroelectric material. It is necessary to preference the appropriate piezoelectric material. The handiest piezoelectric material is PVDF and PZT. For getting higher output voltage for quite a number pressure it is necessary to select the pleasant piezoelectric material. As we practice a range of strain utilized to the piezoelectric cloth the one-of-a-kind voltage readings corresponding to the pressure is displayed. The PZT (lead Zirconate titavate) has extra benefit than PVDF.

PZT is modified lead zirconate titanate. The format of the PZT is Soft and Hard with the refer to the dipole or domain. It is categorized below ferroelectric fabric for regular purposes the Soft ferroelectric material is used it is additionally a reversible process. The Hard PZT cloth is used in excessive degree sound applications. For purposes of special usage the extraordinary kind of materials are used to make the transducer, and proven with the aid of technical implementation and checked individually.

\section{Preparation of Epoxy Resin and Hardener}

First Epoxy Resin and Hardener were mixed in the ratio of 10:1. Accelerators are added $2 \mathrm{ml}$ for $100 \mathrm{~g}$ of resin with drop by drop carefully.

\section{Mould Preparation}

Mould was once fabricated with a mallex sheet of $50 \times 50 \mathrm{~cm}$ dimension and rubber block piece used to be pasted on the dimensions of $300 \mathrm{~mm} \times 300 \mathrm{~mm}$ on 4 sides. The fabrication used to be carried out thru the hand lay-up technique. Before lay-up system the mold has been utilized with a releasing agent to insure that the art will not adhere to the mould .The pinnacle and bottom plates are included with mallex sheet and the fibers, the use of resin compressed to keep away from the particles from getting into composite components in the course of curing.

\section{Fabrication of Composites}

The E-Glass fiber mat was taken as reinforcement materials and epoxy resin as matrix materials to fabricate composites by process of hand lay-up methods. Moulds were prepared in its dimensions of $50 \times 50 \mathrm{~cm}$ was first manufactured for composite fabrication. The composite samples are prepared by different compositions by varying the percentage of fiber weight content such as $(10 \%, 20 \%, 30 \%$, and 40\%) in this composite material. First Epoxy resin and MEKP Catalyst were mixed in the ratio of 10:1. Thus Accelerators are added $2 \mathrm{ml}$ for $100 \mathrm{~g}$ of resin mixture and apply on the mould. A 
releasing agent is used in this mould to release mallex sheets to facilitate easy removal of the composite from the mould after curing. Then place a mallex sheet over the resin and fiber. Then place the sisal fibers mat on the applied resin. Laminas of glass fibers are placed one by one alternatively and resins are applied in between the layers of lamina. To form laminated composites with four layers of lamina of e-glass fiber woven mats. The entrapped air bubbles (if any) are removed carefully with a sliding roller and the mould was closed for curing at a temperature of $30^{\circ} \mathrm{C}$ for $24 \mathrm{~h}$ at a constant load of $10 \mathrm{~kg}$.

After curing, the composites are extracted from the mould plate. Fabricated samples are placed in dry place for improving solid gel strength of the samples. Again repeat the same process for all samples preparation of hybrid natural composites.

\section{PHOTOGRAPHY}

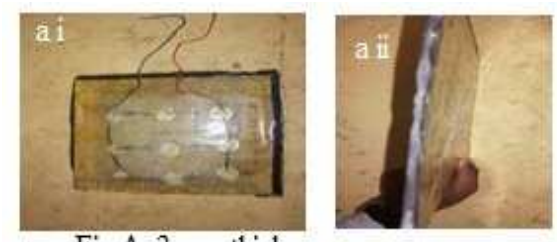

Fig A: 3 mm thickness

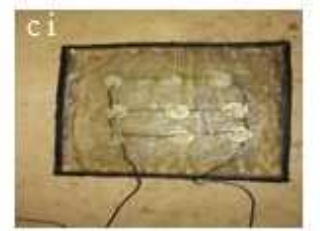

Fig C: $7 \mathrm{~mm}$ thickness

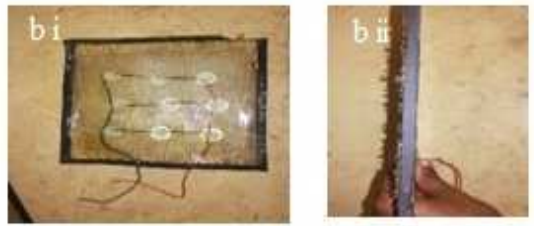

Fig B: $5 \mathrm{~mm}$ thickness

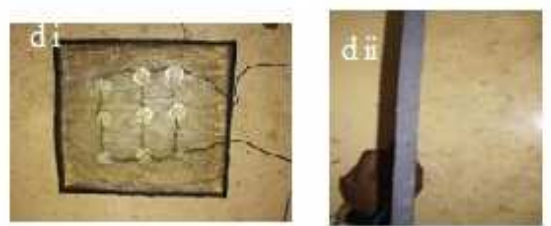

Fig D: $10 \mathrm{~mm}$ thickness

Figure 1: Photography of Polymer Composite Tiles.

\section{WORKING OF COMPOSITE TILES}

Piezoelectric crystal is categorized underneath ferroelectric material. When we provide mechanical stress it will convert it in to electrical energy. A tile made by means of piezoelectric material is made. When we supply mechanical pressure can be either from the weight of the moving motors or from the weight of the human beings taking walks over it, the tile due to piezoelectric fabric it will transformed in to electrical power in the shape of AC. The received AC is now not in steady nation so a bridge rectifier is used to convert variable $\mathrm{AC}$ to constant $\mathrm{DC}$ and stored in battery. The saved $\mathrm{DC}$ is once more transformed in to AC by using inverter the transducer is convert the one form of electricity into any other structure of energy. Here, piezoelectric transducer is mechanical energy convert into the electric powered energy. When we provide mechanical stress it will convert it in to electrical energy. A tile made through piezoelectric material is composite When we give mechanical pressure can be either from the weight of the moving from the weight of the people walking over it, the tile due to piezoelectric material it will converted in to electrical energy in the form of AC. The obtained AC is not in steady state so a bridge rectifier is used to convert variable AC to constant DC and stored in battery.

\section{CALCULATIONS}

As we know the pressure is directly proportional to amount of power generated P $\alpha$ Wt. Here we take the constant of proportionality as $\mathrm{K}$, then the equation becomes,

$$
\mathbf{P}=\mathbf{K} \mathbf{W} .,
$$


Where,

К- Constant of proportionality,

Wt.-weight

P- Power.

We know that for $\mathrm{Wt} .=50 \mathrm{~kg}$, we get the value of

Voltage $=4 \mathrm{~V}$ and

Current $=0.015 \mathrm{~A}$.

Then,

We can say that for $50 \mathrm{~kg}$ we get power

Power $=$ V X I $=0.06 \mathrm{~W}$

From this we can find the value of $\mathrm{K}$,

$\mathrm{K}=\mathrm{P} / \mathrm{Wt} .=0.06 / 50=0.0012$

Table 1

\begin{tabular}{|c|c|c|c|c|}
\hline S. No & Wt. ( kg) & Voltage (Volt) & Current (Amp) & P (watt) \\
\hline 1 & 10 & 1.2 & 0.005 & 0.006 \\
\hline 2 & 20 & 2.5 & 0.009 & 0.023 \\
\hline 3 & 50 & 4 & 0.015 & 0.06 \\
\hline 4 & 75 & 5 & 0.021 & 0.10 \\
\hline
\end{tabular}

\section{CONCLUSIONS}

The principle aim of this paper is to generate strength in a nonconventional, nonpolluting form of power can be harvested and keep economically. The electric strength is produced from the mechanical strain to electrical strength by means of piezoelectric fabric (PZT). The PZT (Lead Zirconate titanate) has used to generate electric power, because it is without problems polarized and low field strength, excessive coupling factor. The (PZT) is most reliable in all traits than different transducers. In future the piezoelectric is predominant source to generate electric powered energy. With future development in the subject of electronics higher manufactured piezoelectric crystals and better choice of place of installation to get more electrical energy can be generated. It is completely relevant for the huge quantity of peoples taking walks areas. In this way of strength manufacturing is Ego-friendly and no pollution. In Future power era is piezoelectric impact is plays a necessary role. This method of electricity manufacturing value effective.

\section{REFERENCES}

1. Review on Foot Step Power Generation By Piezoelectric Transducer (2015) K.Vineesh, Amarnath.K.TM.Lavanya,R.A.Priya, International Journal of Applied Engineering Research, ISSN 0973-4562 Vol. 10 No.4 (2015)

2. Energy Regeneration By Using Piezoelectric Plates(Sensors) In Efficycle Chaudhari Kalpesh1, ChewaleAvinash, GangurdeSiddhant, Dr. S.N. Shelke, International Research Journal of Engineering and Technology (IRJET) Volume: 06 Issue: 01, Jan 2019 
3. Biswajit Jena, S.Z Khan, Bipin Bihari Mohanty \& Swati Surabhi, “Experimental Study on Effect of Fiber Orientation on the Tensile Properties of Fabricated Plate Using Carbon Fiber “, International Journal of Civil Engineering (IJCE), Vol. 5, Issue 4,pp. 9-16

4. A Novel Approach to Recycle Energy Using Piezoelectric Crystals Arjun A.M., Ajay Sampath, SandhyaThiyagarajan, and Arvind V, International Journal of Environmental Science and Development, Vol. 2, No. 6, December 2011

5. Advanced Foot Step Power Generation Piezo-Electric Sensors, Anirudhamchavam,ShyamLakhadive,VaibhavPondhe, Prof. Vineeta Philip, International journal of Advance Research, Ideas and Innovationas in Technology.

6. Generation of Power through Simple Foot StepsusingPiezoelectric Sensor, PallaviPatil, $H$ M Preeti, Dr.BaswarajGadgay, International Journal for Research in Applied Science \& Engineering Technology (IJRASET), Volume 6 Issue VII, July 2018

7. Anselm E. O. Eneh, "Application of Recycled Plastics and its Composites in the Built Environment “, BEST: International Journal of Management, Information Technology and Engineering (BEST: IJMITE), Vol. 3, Issue 3, pp. 916

8. Footstep Power Generation Using Piezo Electric Transducers, KiranBoby, Aleena Paul K, Anumol.C.V, Josnie Ann Thomas, Nimisha K.K Dept of EEE, MACE, Kothamangalam, International Journal of Engineering and Innovative Technology (IJEIT) Volume 3, Issue 10, April 2014.

9. M. Boopalan, M. Niranjana, M. J. Umapathy, Study on the mechanical properties and thermal properties of jute and banana fiber reinforced epoxy hybrid composites, Composites: Part B; 2013; 51:54-57.

10. Bledzki AK, Mamun AA, Faruk $O$, Abaca fibre reinforced PP composites and comparison with jute and flax fibre PP composites, Express Polymer Letters; 2007;1:755-762.

11. Mukhopadhyay S. S., Fangueiro R. R, Yusuf A, Banana fibers - variability and fracture behaviour, Journal of Engineered Fiber and Fabrics; 2008;3:1-7.

12. Benítez AN, Monzón MD, Angulo I, Ortega Z, Hernández PM, Marrero MD, Treatment of banana fiber for use in the reinforcement of polymeric matrices, Measurement; 2013;46:1065-1073.

13. Anurodh Mishra, "Overview Study of the Machining of Composite Materials “, IMPACT: International Journal of Research in Engineering \& Technology (IMPACT: IJRET), Vol. 4, Issue 7, pp. 1-8

14. M.Sakthive, S.Ramesh, Mechanical Properties of Natural Fibre (Banana, Coir, Sisal) Polymer Composites. SCIENCE PARK ISSN: 2321 - 8045 Vol-1, Issue-1, July 2013

15. Maha M. Ibrahim, Alain Dufresne, Waleed K. El-Zawawy, Foster A. Agblevor" in their research work on "Banana fibers and microfibrils as lignocellulosic reinforcements in polymer Composites".

16. J.L. Guimarães , F. Wypych, C.K. Saul, L.P. Ramos, K.G. Satyanarayana, in their research work on "Studies of the processing and characterization of corn starch and its composites with banana and sugarcane fibers from Brazil".

17. T. Balarami Reddy, "Mechanical Performance of Green Coconut Fiber/HDPEComposites by Using Flexural Strength”, International Journal of MechanicalEngineering (IJME), Vol. 3, Issue 1, pp. 53-66

18. S.U. Lokubalasooriya, S. M. Egodage, B. A.J.K. Premachandra studied about the "Banana fiber filled natural rubber compounds: the effect of filler loading and the coupling agent". 
19. Joseph and Thomas studied" The Effect of chemical treatment on the tensile and dynamic mechanical properties of short sisal fiber reinforced low density polyethylene composites". 